\title{
¿Extra ecclesiam nulla salus? Salvación de los no católicos y hermenéutica de la continuidad en la Lumen gentium
}

\section{Extra Ecclesiam Nulla Salus? Salvation of Non-Catholics and Hermeneutics of Continuity in Lumen Gentium}

\author{
Anthony Lourimar Siqueira de QueIRós \\ Ateneo Pontificio Regina Apostolorum. Roma, Italia \\ anthony.ls.queiros@gmail.com \\ (iD https://orcid.org/0000-0002-9576-610X
}

\begin{abstract}
Resumen: Este artículo presenta una lectura de los números 14 a 16 de la Constitución Dogmática Lumen gentium, sobre la posibilidad de salvación para los no-católicos, dentro del marco de la "hermenéutica de la reforma en la continuidad", propuesta por el papa Benedicto XVI. En diálogo con los teólogos que han tratado este tema desde el Concilio Vaticano II (Philips, Sullivan, Sesboüé y Canobbio), se analiza aquí las líneas de continuidad e innovación que se encuentran en la Lumen gentium, identificando los elementos doctrinales esenciales del axioma extra ecclesiam nulla salus y describiendo la nueva síntesis operada en el Concilio.
\end{abstract}

Palabras clave: Lumen gentium, extra ecclesiam nulla salus, hermenéutica de la continuidad, eclesiología, Suprema haec sacra, Concilio Vaticano II

\begin{abstract}
This article offers a reading of numbers 14 to 16 of the Dogmatic Constitution Lumen Gentium, on the possibility of salvation for non-Catholics, within the framework of the "hermeneutics of reform in continuity", as proposed by Pope Benedict XVI. In dialogue with theologians who treated this theme since the Vatican II (Philips, Sullivan, Sesboüé, and Canobbio), it analyses the lines of continuity and innovation found in Lumen Gentium, identifies the essential doctrinal elements in the axiom Extra Ecclesiam Nulla Salus, and describes the new synthesis drafted at the Council.
\end{abstract}

Keywords: Lumen Gentium, Extra Ecclesiam Nulla Salus, hermeneutic of continuity, ecclesilogy, Suprema haec sacra, Second Vatican Council 


\section{INTRODUCCIÓN}

Recientemente el papa Francisco ha subrayado la necesidad de"llevar adelante" el Concilio Vaticano II en la Iglesia, ${ }^{1}$ y ha resaltado que su interpretación no puede ser una cuestión de arbitrio personal, sino que debe ser hecha en comunión con la Iglesia. ${ }^{2}$ Tales afirmaciones apuntan, una vez más, a las cuestiones sobre la interpretación y recepción del Vaticano II que han acompañado la Iglesia desde el mismo Concilio. De la liturgia al ecumenismo, de la libertad religiosa al papel de los seglares, la teología y pastoral de la segunda mitad del siglo xx e inicios de este nuestro siglo ha debido asimilar, interpretar y aplicar el magisterio conciliar, frecuentemente no sin grandes dificultades.

Mientras algunas de estas cuestiones han recibido gran visibilidad, otras han sido frecuentemente dejadas de lado en la pastoral, por la aparente dificultad de conciliarlas con la nueva orientación de la praxis eclesial post-conciliar. Y la cuestión de la necesidad de la Iglesia para la salvación es una de ellas. La afirmación latina extra ecclesiam nulla salus cayó prácticamente en desuso en la catequesis y la predicación cristiana, y teológicamente es recordada más como una formula histórica que como un axioma válido para la vida de la Iglesia contemporánea. Sin embargo, encontramos en Lumen gentium la afirmación en positivo de la necesidad de la Iglesia para la salvación, ${ }^{3}$ el Catecismo de la Iglesia Católica la repite, ${ }^{4}$ y la declaración Dominus Iesus, del 2000, la emplea y explica. ${ }^{5}$

¿Cómo entender, entonces, la necesidad de la Iglesia para la salvación a la luz de la doctrina conciliar? ¿La fórmula extra ecclesiam

1 FrANCISCO, Incontro del Santo Padre con i gesuiti, 23 de septiembre de 2018. <http:// www.vatican.va/content/francesco/it/speeches/2018/september/documents/papa-francesco_20180923_gesuiti-vilnius-lituania.html>.

2 Cf. Francisco, Discurso del Santo Padre Francisco a los partecipantes en la reunión organizada por la oficina nacional de catequesis de la conferencia episcopal italiana, 30 de enero de 2021. <http://www.vatican.va/content/francesco/es/speeches/2021/ january/documents/papa-francesco_20210130_ufficio-catechistico-cei.html>.

3 Cf. Concilio Vaticano II, Lumen gentium 14-16 cf. Enchiridion Vaticanum, Edizioni Dehoniane Bologna, Bologna 1997, v. 1, 498-504. (de ahora en adelante, LG).

4 Cf. Catechismus Catholicae Ecclesiae, Libreria Editrice Vaticana, Città del Vaticano 1997, n. 846.

5 Cf. Congregación para la Doctrina de la Fe, Dominus Iesus, 20 (en especial la nota 82 a este número). 
nulla salus es todavía válida? De las respuestas a tales preguntas parte una serie de consecuencias no solamente teóricas, sino de gran relevancia práctica para la pastoral, las misiones, el ecumenismo y tantos aspectos de la vida de la Iglesia.

En las décadas posteriores al Concilio Vaticano II tres obras ofrecieron un rico análisis histórico y conceptual sobre el tema, desde perspectivas y con conclusiones diversas. El jesuita americano Francis Sullivan, ${ }^{6}$ su correligionario francés Bernard Sesboué, ${ }^{7}$ y el teólogo italiano Giacomo Canobbio ${ }^{8}$ han tratado el tema en obras de gran valor, que serán una referencia constante en este artículo. Sin embargo, las tres obras, en modalidades diversas, parecen suponer una ruptura entre la doctrina anterior al Vaticano in y el modo como Lumen gentium ha tratado el tema, sea negando, sea redimensionando en modo radical el valor de la afirmación extra ecclesiam nulla salus.

Este artículo toma un camino diverso, un camino sugerido por el papa Benedicto XVI en su célebre discurso sobre las dos hermenéuticas del Concilio Vaticano II. ${ }^{9}$ El Pontífice propone una lectura del Concilio como una auténtica reforma, pero en continuidad con la Tradición y el Magisterio precedentes, y no como una ruptura tendente a crear una nueva Iglesia. Tomando esta hermenéutica como propuesta de lectura, este artículo se propone identificar los elementos de continuidad y los elementos de cambio en la eclesiología conciliar que permiten explicar el tratamiento dado por la Lumen gentium a la relación entre Iglesia y salvación. ${ }^{10}$

6 Cf. Francis Sullivan, Salvation Outside the Church?, London, Geoffrey Chapman, 1992.

7 Cf. Bernard Sesboute, Fuera de la Iglesia no hay salvación, Bilbao, Ediciones Mensajero, 2006, traducido del original francés Hors de l'Église pas de salut, Paris, Desclée de Brouwer, 2004.

8 Cf. Giacomo CANobio, Chiesa perché. Salvezza dell'umanità e mediazione ecclesiale, Milan, San Paolo, 1994.

9 Cf. Benedicto XVI, Discurso a los cardenales, arzobispos, obispos y prelados superiores de la curia romana, 22 de diciembre de 2005. < https://www.vatican.va/ content/benedict-xvi/es/speeches/2005/december/documents/hf_ben_xvi_ spe_20051222_roman-curia.html >.

10 Compartimos, por lo tanto, la orientación de Matthew J. RAmage, "Extra Ecclesiam Nulla Salus and the Substance of Catholic Doctrine: Towards a Realization of Benedict XVI's «Hermeneutic of Reform»", Nova et Vetera 14/1 (2016) 295-330, aunque la metodología de este artículo sea diversa a la suya. 
Por lo tanto, la exposición se divide en tres partes: en la primera, se presenta una síntesis de la consideración del tema en la teología y el Magisterio en la primera mitad del siglo xx. En la segunda, se hace un análisis del tema en la Lumen gentiun. Finalmente, las dos partes serán puestas en comparación, delineando unas conclusiones de carácter histórico, interpretativo y doctrinal.

\section{EXTRA ECCLESIAM NULLA SALUS EN LA TEOLOGÍA Y MAGISTERIO DE LA PRIMERA MITAD DEL SIGLO XX}

En 1949 el Santo Oficio envió una carta al arzobispo James Cushing, de Boston, conteniendo lo que hoy se conoce como el decreto Suprema haec sacra. ${ }^{11}$ El decreto era una respuesta doctrinal a la controversia causada por la predicación del sacerdote jesuita Leonard Feeney y sus asociados del Saint Benedict Center en aquella diócesis americana. Estos, a partir de 1947, defendían una interpretación estricta de la afirmación extra ecclesiam nulla salus, negando cualquier posibilidad de salvación para quien se encontrara visiblemente fuera de la Iglesia al momento de la muerte. Además, dirigían fuertes críticas a la jerarquía e instituciones del catolicismo americano, que juzgaban demasiado laxas al proponer esta doctrina, por temor a perder la simpatía pública en un país multirreligioso como los Estados Unidos de América. El asunto terminó con la definición del Santo Oficio y la excomunión de Feeney en 1953, que se negó a renunciar a sus posiciones. ${ }^{12}$

El interés del decreto del Santo Oficio del 1949 consiste en que por primera vez tenemos un documento doctrinal que expone en detalle la enseñanza de que fuera de la Iglesia no hay salvación intentando a la vez armonizarla con la conciencia desarrollada gradualmente en los siglos posteriores a su formulación más estricta, presente en la bula Cantate Domino, del Concilio de Florencia en $1442 .{ }^{13}$ ¿En qué consistió tal cambio?

11 Cf. Congregación Del Santo Oficio, decreto Suprema haec sacra, 08 de agosto de 1949, in Heinrich DenZinger - Peter Hünermann (ed.), El Magisterio de la Iglesia, Barcelona, Herder, 1999 (de ahora en adelante DH), n. 3866-3873.

12 Para una descripción detallada de los eventos, desde una perspectiva simpática a Feeney, Gary PotTer, After the Boston Heresy Case, Monrovia, Catholic Treasures Books, 1995.

13 Cf. DH 1351. 
Durante la Edad Media el mundo conocido era cristiano o considerado como voluntariamente opuesto a la religión cristiana. Sin embargo, a partir de las grandes navegaciones, se descubren poblaciones enteras que jamás habían escuchado el anuncio del evangelio. ¿Estarían todos estos pueblos condenados al infierno? Además, a partir del siglo xIX en Europa y Norte América el Catolicismo ya no gozaba de una posición hegemónica, y por ello, el problema de la salvación de los no católicos para muchos cristianos se vinculaba directamente con el destino eterno de sus conciudadanos, amigos y familiares. La cuestión adquirió, en consecuencia, un interés vital del que antes carecía.

Por ello, se empezó a admitir la posibilidad de salvación para los no-católicos bajo el concepto de "ignorancia invencible", no solamente entre los teólogos, sino también el mismo magisterio pontificio, a partir de que Pío ix lo empleara. De hecho, aquel pontífice, en la encíclica Quanto conficiamur moerore, del 1863, afirmaba:

aquellos que sufren ignorancia invencible de nuestra santísima religión, que cuidadosamente guardan la ley natural y sus preceptos, esculpidos por Dios en los corazones de todos y están dispuestos a obedecer a Dios y llevan vida honesta y recta, pueden conseguir la vida eterna, por la operación de la virtud de la luz divina y de la gracia. ${ }^{14}$

Sin embargo, tal afirmación no pretendía negar la validez del axioma de que fuera de la Iglesia no hay salvación, al cual el mismo documento se refería. Es más, lo reafirmaba explícitamente, llegando a darle el calificativo de catholicum dogma. ${ }^{15}$ ¿Cómo es posible, entonces, afirmar ambas cosas? Conciliar tales afirmaciones será la tarea de la soteriología en los años que separan Quanto conficiamur moerore del decreto Suprema haec sacra.

En 1913, el jesuita francés Jean Vincent Bainvel resumía las posiciones sobre el asunto en cuatro vías distintas que intentaban explicar la aparente contradición: ${ }^{16}$

\section{DH 2866.}

DH 2867.

16 Cf. Jean Bainvel, Hors de l'Église pas de Salut, Beauchesne, Paris, 1913, citado según Geertjan Zuijdwegt, "Salvation and the Church: Feeney, Fenton and the Making of Lumen Gentium", Louvain Studies 37 (2013) 147-178, 154 (doi: 10.2143/LS.37.2.3038710). 
1. Una primera opción distinguía entre necesidad de medio y necesidad de precepto. Si un medio es necesario a un fin, no se puede alcanzar el fin sin tal medio. Por otro lado, en una necesidad apenas de precepto, un medio está vinculado a un fin solamente en virtud de una orden externa. Este sería el caso de la necesidad de la Iglesia para la salvación, según tal explicación. La Iglesia es necesaria para la salvación solamente porque Dios así lo quiso, y por lo tanto la adhesión a ella no es necesaria para quien, con buena fe, ignora esta obligación.

2. Una segunda posición distinguía entre modo ordinario y extraordinario de salvación. La Iglesia sería el modo ordinario de salvación, mientras Dios tendría otros medios extraordinarios para salvar a aquellos que no son miembros de la Iglesia sin culpa de su parte.

3. Una tercera opinión distinguía entre pertenencia al cuerpo y al alma de la Iglesia. Esta distinción entre cuerpo y alma, que viene de san Roberto Belarmino, pasa a ser aplicada al tema de la salvación. ${ }^{17}$ Es necesario pertenecer al alma de la Iglesia, o sea, participar de sus dones espirituales, pero no es estrictamente necesario para la salvación participar de su cuerpo o estructura jerárquica.

4. Finalmente, una última distinción era entre pertenencia in re y pertenencia in voto. Además de una pertenencia explícita y efectiva en la Iglesia (in re) existe otra forma de pertenencia solamente intencional, en deseo (in voto). Este deseo puede ser explícito, en el caso de los catecúmenos, o implícito, en el caso de aquellos que se hallan en ignorancia invencible.

Las dos primeras posiciones no gozaban de gran favor, dado que no explicaban bien cómo todos los salvados se salvarían en la Iglesia, y así parecían no mantener el sentido de la afirmación central de que fuera de la Iglesia no hay salvación. La tercera posición, por el contrario, tenía a su favor una terminología derivada de san Roberto Belarmino y lograba explicar bien el sentido de la distinción hecha por Pío Ix.

17 Roberto Belarmino, De Controversiis Christianae Fidei adversus Huius Temporis Haereticos, tomo 1, Ingolstadt, 1586, p. 1264, citado según Joseph Clifford FENTON, "The Use of the Terms Body and Soul with Reference to the Catholic Church", The American Ecclesiastical Review 110 (1944) 52-53 (48-57). En este artículo, publicado en el año siguiente a la encíclica Mystici Corporis, el teólogo americano y futuro peritus en el Concilio busca explicar cómo los términos cuerpo y alma de la Iglesia, pasan a ser utilizados en un sentido distinto de aquel que les dio Belarmino en su obra, y, según él, erróneo. 
Ella fue predominante en este período, sea con la distinción entre alma y cuerpo de la Iglesia, sea con la distinción entre Cuerpo Místico e Iglesia Visible que le sucederá. ${ }^{18}$

Esta distinción, sin embargo, no estaba carente de riesgos para la teología. Una contraposición entre cuerpo y alma de la Iglesia se asemejaba a la distinción luterana entre la iglesia visible y la iglesia espiritual. En la encíclica Mystici Corporis, del 1943, el documento eclesiológico más completo antes del Vaticano II, el papa Pío XII se opuso decididamente a la distinción entre un Cuerpo Místico de Cristo invisible y una Iglesia visible. El Cuerpo Místico de Cristo es la Iglesia Católica, y para ser miembro de ella se requieren tres cosas: la recepción del bautismo, la profesión de la fe verdadera y la no separación de la estructura jerárquica de la Iglesia. ${ }^{19}$ Estos criterios, marcadamente externos y tomados de la tardo-escolástica moderna, fueron formulados por Báñez y popularizados por Roberto Belarmino. ${ }^{20}$

Por lo tanto, una interpretación de la pertenencia a la Iglesia que divida Iglesia institucional y Cuerpo Místico de Cristo no parece ser aceptable. ¿Qué consecuencias son implicadas para el tema de la salvación de aquellos que no son miembros de este cuerpo? Hacia el final del documento, se dirige una exhortación a todos los no-católicos para que se unan a la Iglesia:

También a aquellos que no pertenecen al organismo visible de la Iglesia católica (qui ad adspectabilem non pertinent Catholicae Ecclesiae compagem) ... se esfuercen por salir de ese estado, en el que no pueden estar seguros de su propia salvación eterna; pues, aunque por cierto inconsciente deseo y aspiración (etiamsi inscio quodam desiderio ac voto) están ordenados al Cuerpo místico del Redentor, carecen, sin embargo, de tantos y tan grandes dones y socorros celestiales, como solo en la Iglesia católica es posible gozar. ${ }^{21}$

Este párrafo testimonia una elección cuidadosa del lenguaje, en consonancia con la tesis central de la encíclica. Para describir el aspecto visible de la Iglesia se utiliza compago, traducido en español como organismo, para evitar así cualquier referencia a un cuerpo visible en contraposición a un alma invisible de la Iglesia. Por otro lado,

\footnotetext{
18 Cf. Sullivan, Salvation Outside the Church?, 123-128.

19 Cf. Pío xII, Mystici Corporis 10, cf. DH 3802.

20 Cf. Joseph Clifford Fenton, The Catholic Church and Salvation, Westminster, The Newman Press, 1958, 77.

21 DH 3821.
} 
el documento reconoce que puedan existir hombres que estén ordenados (ordinentur) al Cuerpo Místico del Redentor, aunque no sean miembros de él en el sentido propio de que se hablaba al inicio de la encíclica. Del estado de estos en cuanto a la salvación eterna, se afirma que no es seguro, pues la plenitud de los medios de salvación se encuentra solamente en la Iglesia. Sin embargo, no se excluye que puedan salvarse, precisamente por medio de esta vinculación.

Por fin, tales personas se ordenan a la Iglesia inscio quodam desiderio ac voto, o sea, a través de un deseo que puede ser inconsciente. Pío XII parece así sostener que aquellos que no son miembros efectivos del organismo visible de la Iglesia pueden estar ordenados a él por medio de un deseo y aspiración, que les daría una posibilidad de salvación. De la unión de Mystici Corporis con los documentos de Pío IX, se parecía concluir la teoría del votum Ecclesiae como medio de salvación para los que están en ignorancia invencible. Según esta explicación, aquellos que viven en ignorancia de la verdad evangélica sin culpa propia, pero se esfuerzan por obedecer a Dios según los preceptos de la ley natural y una vida honesta, pueden estar ordenados a la Iglesia por un deseo y aspiración inconscientes y, por lo tanto, pueden obtener la salvación.

Era esta una interpretación bastante restrictiva, por la identificación entre Iglesia y Cuerpo Místico, que creaba problemas para los teólogos que querían dar a la fórmula un sentido inclusivo. Así, varios teólogos durante la década de los 40 buscaron hacer una expositio reverentialis de la encíclica, o sea, aceptando el texto como tal, introdujeron una serie de distinciones que atenuaban su sentido. ${ }^{22}$ Por esto, la encíclica Humani generis del 1950 catalogó explícitamente como errónea la intepretación de Mystici Corporis en sentido demasiado amplio:

Algunos no se consideran obligados por la doctrina — que, fundada en las fuentes de la revelación, expusimos Nos hace pocos años en una Encíclica-, según la cual el Cuerpo místico de Cristo y la Iglesia católica romana son una sola y misma cosa. Otros reducen a una pura fórmula la necesidad de pertenecer a la verdadera Iglesia para conseguir la salud eterna. ${ }^{23}$

22 Cf. Sesboute, Fuera de la Iglesia no hay salvación, 217-222.

23 Pío xil, Humani Generis 21 (12 de agosto de 1950), en Fernando Guerrero (ed.), El Magisterio Pontificio Contemporáneo, tomo 1, Madrid, BAC, 1992, 234. 
Este es el contexto histórico y doctrinal del decreto Suprema haec sacra. ¿Cuáles son los puntos doctrinales expuestos en él? ¿Cómo se concilian la necesidad de la Iglesia para la salvación y la posibilidad de salvarse para los no-católicos? El documento puede ser resumido esquemáticamente en los siguientes puntos:

1. Se reafirma la validez de la expresión extra ecclesiam nulla salus. Más aún, se afirma que esta es enseñanza infalible de la Iglesia y se le da el calificativo de dogma. ${ }^{24}$

2. Afirma que hay una necesidad de precepto de entrar en la Iglesia, y que como tal esta se aplica a todos los hombres que conocen esta necesidad como voluntad divina. Por ello, están excluidos de la salvación todos los que conociendo el precepto rechazan obedecerlo. ${ }^{25}$

3. Además, la necesidad de la Iglesia no es apenas de precepto, sino también de medio: la Iglesia es medio de salvación sin el cual nemo intrare valeat regnum gloriae caelestis. ${ }^{26}$ Esta necesidad de medio, sin embargo, no es intrínseca, sino extrínseca, basada en la voluntad positiva de Dios que quiso instituir la Iglesia. ${ }^{27}$

4. Por ello, es posible, en ciertas circunstancias, participar de la acción salvífica de la Iglesia por medio de una adhesión solamente en voto o deseo. Este deseo es explícito en el caso de los catecúmenos, pero Dios también acepta el deseo implícito en aquellos que sufren una ignorancia invencible. Este deseo implícito está contenido en la buena disposición del alma para conformar su voluntad con la voluntad de Dios. ${ }^{28}$ Se explicita aquí la doctrina del votum Ecclesiae.

5. Sin embargo, no cualquier deseo implícito es suficiente para la salvación, sino que este debe incluir la fe y la caridad sobrenaturales. ${ }^{29}$

Así pues, el decreto parece aclarar la cuestión doctrinal pendiente, asumiendo como propia la teoría de la participación en la Iglesia in re o in voto, y declarando que esta última forma de participación es suficiente para la salvación, si está acompañada de la fe y caridad sobrenaturales, aun cuando este deseo de pertenecer a la Iglesia sea apenas implícito, en aquellos que padecen ignorancia invencible.

\footnotetext{
Cf. DH 3866.

Cf. DH 3867.

DH 3868.

Cf. DH 3869.

Cf. DH 3870.

29 Cf. DH 3872.
} 
Efectivamente, Suprema haec sacra llega a una explicación definitiva de la cuestión dentro de las categorías eclesiológicas y soteriológicas anteriores al Vaticano ir. Pero precisamente estas categorías pasaban por un proceso de profundo cambio en el desarrollo teológico en los mismos años en que se escribía el decreto.

\section{LA IGLESIA Y LA SALVACIÓN EN LUMEN GENTIUM}

Para comprender el cambio de perspectiva operado por la Lumen Gentium en el tema de la Iglesia y la salvación, es necesario identificar las líneas de desarrollo teológico anteriores al Concilio, en especial en los campos de la eclesiología y de la soteriología. Esta sección buscará presentar un sumario de tales líneas de desarrollo a partir de dos obras de síntesis publicadas en la primera mitad de la década de 60. A continuación veremos cómo estas ideas encuentran acogida en el texto conciliar.

\subsection{El desarrollo teológico previo al Concilio}

En 1960 el teólogo jesuita Maurice Eminyan publicó un libro llamado The Theology of Salvation, ${ }^{30}$ en el que busca hacer una presentación sintética de todo lo escrito sobre el tema de la necesidad de la Iglesia para la salvación entre 1943 y 1958. Según el autor, "el problema de la salvación de los infieles es, sin duda, uno de los más ampliamente tratados en la literatura teológica actual" ${ }^{31}$

Además de su valor sintético, el libro capta el cambio de espíritu que se daba en aquellos años, pues aún manteniendo una conclusión bastante semejante a la de Suprema haec sacra, el autor deja ver en las obras que analiza algunos principios de cambio que implican un tentativo de entender la participación de la Iglesia en la obra de la salvación en una perspectiva más amplia. Algunos elementos del cambio de mentalidad teológica operado en este tiempo sobresalen en la obra.

El primero de estos elementos radica en una valoración más positiva de las religiones no-cristianas, que nace a partir de la labor

30 Cf. Maurice Eminyan, The Theology of Salvation, Jamaica Plains, Boston, MS, St. Paul Editions, 1960.

31 "The problem of the salvation of the infidels is undoubtedly one of the most widely treated in current theological literature" (EMINYAN, The Theology of Salvation, 17; traducción mía). 
misionera y de los estudios etnológicos de finales del siglo XIX e inicios del siglo xx. De hecho, una parte considerable de los trabajos que cita el P. Eminyan son escritos de misioneros en culturas no cristianas, que enfatizan la presencia de valores positivos o aún de elementos sobrenaturales entre los pueblos que evangelizan. ${ }^{32}$

El segundo elemento es el nuevo entendimiento de la relación entre natural y sobrenatural. Esta cuestión fue una de las más debatidas en la teología católica a partir de la publicación del libro Surnaturel, de Henri de Lubac, en 1946, en el cual el jesuita niega la existencia de una doble finalidad natural y sobrenatural en el ser humano y atribuye la creación de esta división a la escolástica renascentista. ${ }^{33}$ Entre los teólogos que gradualmente van aceptando esta concepción de una división menos rígida entre lo natural y lo sobrenatural, sobre todo por influjo de una filosofía de matriz personalista, es difícil concebir las acciones morales naturales del hombre a parte de una apertura sobrenatural, y por lo tanto, en cierto modo, de un valor salvífico. ${ }^{34}$ Las consecuencias de este cambio para la doctrina de la salvación de los no-católicos son claras: los mismos actos morales del ser humano ya estarían de algún modo conectados con la gracia, y la bondad propia del ser humano tendría un carácter salvífico. En el libro de Eminyan esta postura se ve en especial en la exposición acerca de la teología de Yves Congar. ${ }^{35}$

32 Cf. EminYan, The Theology of Salvation, 28-41.

33 Cf. Henri De Lubac, Surnaturel: Études historiques, Paris, Desclée de Brouwer, 1991. Algunas sugerencias bibliográficas sobre la importancia de este debate para la teología del siglo xx en Serge Bonino (éd.), "Surnaturel: Une controverse au coeur du thomisme au XXe siècle. Actes du colloque organisé par l'Institut SaintThomas d'Aquin les 26-27 mai 2000 à Toulouse", Revue Thomiste 101/1-2 (2001); Nicholas Healy, "Henri de Lubac on Nature and Grace: A Note on Some Recent Contributions to the Debate", Communio 35 (2008) 535-564; Guy MansinI, "The Theological Abiding Significance of Henri de Lubac's Surnaturel", The Thomist 73 (2009) 593-619; John Milbank, The Suspended Middle: Henri de Lubac and the Debate concerning the Supernatural, Grand Rapids, MI, Eerdmans, 2006.

34 En un artículo escrito en 1948, en el cual critica las posiciones de De Lubac y Maritain, el jesuita Charles Boyer afirma que la posición de estos teólogos termina por hacer imposible un acto moral que no tenga a la vez, un valor salvífico: Charles BOYER, "Morale et surnaturel", Gregorianum 29 (1948) 527-543. En un artículo publicado en 1950 (Eine Antwort), Karl Rahner afirma precisamente este principio. El artículo fue posteriormente ampliado e incluido en Karl RAHNER, "Relationship between Nature and Grace" in Theological Investigations, vol. 1, Baltimore, MD, Helicon Press, 1961. 
Un tercer elemento a tener en cuenta es una distinta comprensión de la participación en la Iglesia, vista no ya en modo unívoco, sino analógico. Un modelo de pertenencia a la Iglesia con distintos grados es propuesto por algunos teólogos, especialmente vinculados al movimiento ecuménico. ${ }^{36}$ Así, la acción salvífica eclesial es concebida de un modo más espiritual que jurídico, y la gracia puede llegar, por medio de la Iglesia, aun a aquellos hombres que no se encuentran bajo su campo de acción visible, como defiende el autor en su síntesis general especulativa. ${ }^{37}$

Estas ideas seguirán desarrollándose en los años sucesivos a la publicación del libro de Eminyan, que corresponden a los años del Vaticano II. Esto lo demuestra otra recensión, publicada cinco años más tarde en la recién-fundada revista Concilium por el dominico Boniface Willems. Este artículo, con menos referencias directas y mayor interés teorético, intenta cubrir el desarrollo teológico a partir de $1950 .^{38}$

Willems apunta al trabajo de investigación histórica sobre el origen patrístico del adagio extra ecclesiam nulla salus en su contexto propio, ${ }^{39}$ algo que será tenido en cuenta en la elaboración de Lumen gentium. ${ }^{40}$ Hace ver, además, las mismas tendencias ya subrayadas en la obra de Eminyan, pero tomando planteamientos más radicales. Una parte importante del artículo está dedicada al modo como los teólogos tratan los vestigia Ecclesiae, o sea, los elementos de genuina realidad eclesial en comunidades e iglesias cristianas no católicas, ${ }^{41}$ y la vinculación de la misma naturaleza humana a la obra de la redención, llegando a afirmar que "por lo tanto, radicalmente, en su raíz, todo ser humano ya está en la Iglesia, porque la participación [membership] de este pueblo de Dios ya es un aspecto factual de la naturaleza humana" ${ }^{42}$ Este cambio de mentalidad, con los elemen-

\footnotetext{
En especial Charles Journet, in Eminyan, The Theology of Salvation, 170-171.

Cf. EMINYAn, The Theology of Salvation, 222.

Cf. Boniface WiLlems, “Who Belongs to the Church", Concilium 1 (1965) 131-151.

Cf. Willems, "Who Belongs to the Church", 133-135.

Cf. Gérard PHILIPS, L'Église et son mystère au II Concile du Vatican, Paris, Desclée de Brouwer, 1967, 188-194 (traducida al español como Gérard PHILIPS, La Iglesia y su misterio en el Concilio Vaticano II. Historia, texto y comentarios de la Constitución "Lumen Gentium", Tomo I-II, Barcelona, Herder, 1968-1969).

41 Cf. Willems, "Who Belongs to the Church", 141-145.

42 "Radically, in his roots, therefore, every human being is already in the Church, because membership of this People of God is already a factual aspect of human
} 
tos vinculados a él, tendrá un impacto decisivo en la elaboración de la Lumen gentium.

Las obras de Eminyam y Willems se ocupan sobre todo de la valoración de las religiones no-cristianas. Al mismo tiempo crecía en Europa una actitud más positiva entre los católicos en relación a aquellos que no profesaban ninguna religión. La difusión del ateísmo como fenómeno de masa, los contactos más frecuentes entre cristianos y no-creyentes, y la colaboración común en causas sociales contribuyó a este proceso que tendrá también una influencia en el Concilio. ${ }^{43}$

\subsection{La elaboración de la Lumen gentium}

La Constitución Dogmática Lumen gentium, tratará en los párrafos 14 a 16 acerca de la necesidad de la Iglesia para la salvación y de la posibilidad de que los no católicos se salven. ${ }^{44}$ ¿Cómo se relaciona este texto con los puntos que hemos individuado en el decreto Suprema haec sacra?

1. Necesidad de la Iglesia para la salvación: La fórmula extra ecclesiam nulla salus no es utilizada, pero el documento afirma la necesidad de la Iglesia para la salvación, a partir de la Sagrada Escritura y de la Tradición:" (el Concilio) enseña, fundado en la Sagrada Escritura y en la Tradición, que esta Iglesia peregrinante es necesaria para la salvación" ${ }^{45}$ Esta necesidad se vincula a la fe y al bautismo, pero sobre todo, siguiendo la doctrina de Mystici Corporis, al hecho de que la Iglesia es el cuerpo de Cristo, único mediador de la salvación.

2. La necesidad de precepto de adherirse a la Iglesia, y la consecuente exclusión de la salvación para los que conscientemente se niegan a cumplir este precepto es claramente afirmada: "Por lo cual no podrían salvarse aquellos hombres que, conociendo que la Iglesia

nature” (WiLlems, “Who Belongs to the Church”, 145; traducción mía).

43 Este proceso es descrito en Stephen S. Bullivant, The Salvation of Atheists and Catholic Dogmatic Theology, Oxford, Oxford University Press, 2012, 51-59.

44 Cf. Concilio Vaticano II, Lumen gentium 14-16: cf. Enchiridion Vaticanum, Edizioni Dehoniane Bologna, Bologna 1997, v. 1, 498-504. El texto español será citado según la versión: http://www.vatican.va/archive/hist_councils/ii_vatican_council/documents/vat-ii_const_19641121_lumen-gentium_sp.html[consulta: 03-03-2021].

45 Lumen gentium, 14. 
católica fue instituida por Dios a través de Jesucristo como necesaria, sin embargo, se negasen a entrar o a perseverar en ella"46.

3. La necesidad de medio se presenta en forma mucho más matizada. Según Gérard Philips, que dirigió la comisión encargada de escribir la Lumen gentium, aunque no haya una referencia explícita a la distinción entre necesidad de medio y necesidad de precepto, la significación es "suficientemente clara". Hay una "necesidad de medio", que, sin embargo, genera una obligación solamente en la medida en que es conocida. ${ }^{47}$ No obstante, algunos de los padres conciliares temían que la formulación del documento final diera a entender solamente la necesidad de precepto, y no la de medio. ${ }^{48}$

4. La doctrina de la pertenencia a la Iglesia in voto es mencionada explícitamente en relación a los catecúmenos, que "movidos por el Espíritu Santo, solicitan con voluntad expresa ser incorporados a la Iglesia, por este mismo deseo ya están vinculados a ella". ${ }^{49}$ En relación a los bautizados no-católicos, no hay ninguna mención del votum, declarando apenas que estos se encuentran unidos a la Iglesia "por muchas razones (plures ob rationes)" ${ }^{50}$ En relación con los no cristianos, se afirma que estos"se ordenan (ordinantur) al pueblo de Dios de diversas maneras (diversis rationibus)" ${ }^{51}$ Sin mencionar la doctrina del votum, se dice que aquellos que buscan a Dios con un corazón sincero y actúan según su voluntad, conocida por medio de la propia conciencia, bajo el influjo de la gracia divina, pueden alcanzar la salvación.

5. Donde vemos una mayor distancia entre el decreto de 1949 y la Constitución Dogmática es en el tema de la necesidad de la fe y la caridad sobrenaturales incluidas en tal deseo. Tratando de los no cristianos, el Concilio subraya como elemento de salvación apenas el hecho de que busquen seguir a la voluntad de Dios como se manifiesta a sus conciencias. Esto es posible, "bajo el influjo de la gracia" y"no sin la gracia de Dios". ${ }^{52}$ La mención de la gracia parece reconocer la posibilidad de un valor salvífico a ciertas acciones morales

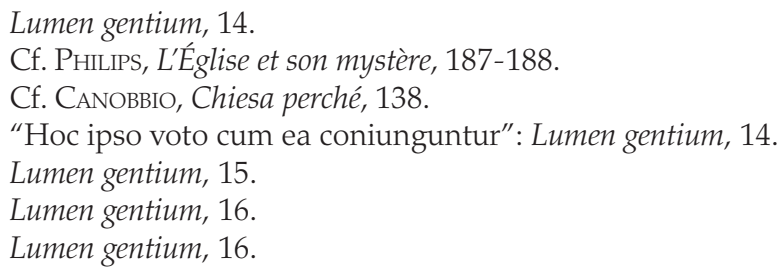


hechas en colaboración con la gracia, aunque estas acciones no sean necesariamente informadas por la fe sobrenatural.

Podemos decir, en resumen, que la doctrina de la necesidad de medio y de precepto de la Iglesia para la salvación es mantenida, aunque su alcance sea redimensionado. La formulación de Suprema haec sacra admitía la posibilidad de salvación para los no-católicos si se daban dos elementos: uno negativo (ignorancia invencible acerca de la verdadera fe) y uno positivo (votum Ecclesiae, aunque implícito, informado por la fe y caridad sobrenaturales). La Lumen gentium trata ambos elementos en modo diverso.

La ignorancia que permitiría a alguien salvarse sin estar plenamente incorporado a la Iglesia es vista no solamente como la de quien jamás ha recibido el anuncio del evangelio, sino más bien como la incapacidad de reconocer en la Iglesia católica la Iglesia instituida por Cristo y necesaria a la salvación. Aquí se recoge un desarrollo doctrinal llevado a cabo a partir de las consideraciones de los teólogos neoescolásticos del siglo XVI, sobre todo Francisco de Vitoria y Bartolomé de Las Casas. A partir de la conquista de América y del rechazo de los indígenas de convertirse inmediatamente al cristianismo, tales teólogos aclaraban que aun aquellos a quienes el evangelio había sido anunciado, pero en forma insuficiente, podían ser excusados en su ignorancia..$^{3}$

Esto, según Francis Sullivan, constituye el gran cambio de paradigma operado por el Concilio. En la interpretación del teólogo jesuita, en las declaraciones preconciliares sobre la salvación de aquellos que se encontraban fuera de la Iglesia, había una presunción general de culpabilidad, de la cual apenas unos pocos se destacarían. Ahora encontramos más bien una presunción de inocencia, que lleva a una visión mucho más optimista en cuanto a la salvación de los no católicos. ${ }^{54}$ De hecho, Philips, comentando la proposición de Lumen gentium sobre los hombres que reconociendo en la Iglesia católica la Iglesia de Cristo se niegan sin embargo a entrar o perseverar en ella, admite que se trata de un caso excepcional, más bien raro. ${ }^{55}$ Por

\footnotetext{
53 Cf. Bullivant, Salvation of Atheists, 135-139.

54 Cf. Sullivan, Salvation Outside the Church?, 151.

55 Cf. PHILIPS, L'Église et son mystère, 187.
} 
su parte, el comentario de Dario Vitali ve en el caso de los que"no se pueden salvar" más bien una excepción. ${ }^{56}$

Pero la doctrina tradicional sobre la salvación afirma que la sola ignorancia no es salvífica. Es necesario también un elemento positivo de unión con la Iglesia. En efecto, el mismo Francisco de Vitoria que defendía que la ignorancia de los habitantes del Nuevo Mundo no era culpable, afirmaba sin embargo que ellos se condenarían por sus pecados mortales o por la idolatría. ${ }^{57}$ En cuanto a este elemento positivo, el Concilio ya no afirma explícitamente la necesidad de un votum Ecclesiae unido a la fe y caridad para que un no-católico esté vinculado a la Iglesia. Más bien encontramos la mención más vaga a diversae rationes.

Este cambio de perspectiva viene posiblemente de tres elementos que hemos individuado en la teología del siglo xx: la valoración positiva de las religiones no-cristianas, la aceptación de la filosofía personalista de la acción humana y la distinta consideración de la realidad de la Iglesia. Este último cambio es esencial. Charles Morerod sostiene que para entender la afirmación de que fuera de la Iglesia no hay salvación, es necesario superar la visión estrictamente jurídica de Belarmino, en pos de una visión más amplia y, según él, más tradicional, que ve en la Iglesia a"todos aquellos que están siendo salvados" ${ }^{58}$ Así la participación en la Iglesia es vista en modo análogo, como lo es la participación en la gracia. Una cita de Philips ilustra bien esta visión:

Toda gracia conferida es una gracia del Hijo encarnado, comunicada por el único y mismo Espíritu, que hace de todos los creyentes el único Cuerpo de Cristo. La gracia presenta, por lo tanto, un aspecto comunitario: ella es de naturaleza social y siempre se refiere a la Iglesia. Precisamento por ello el adagio "Fuera de la Iglesia no hay salvación" conserva su significación para todos los hombres, aunque no de forma idéntica para todos..$^{59}$

56 Cf. Serena Noceti - Roberto Repole (eds.), Comentario ai documenti del Vaticano II. Lumen Gentium (2), Bologna, EDB, 2015, 198.

57 Cf. Bullivant, Salvation of Atheists, 137, citando el De Indis de Francisco de Victoria.

58 Charles Morerod, "No Salvation Outside the Church: Understanding the Doctrine with St. Thomas Aquinas and Charles Journet", The Thomist 75/4 (2011) 524-525 (517-536).

59 “Toute grâce conférée est une grâce du Fils incarné, communiquée par l'unique et même Esprit, qui fait de tous les croyants l'unique Corps du Christ. La grâce 
Sin embargo, tal concepción no está libre de problemas. Desde el punto de vista meramente lógico hay el riesgo de reducir el axioma a una simple tautología. Si "Iglesia" significa aquellos que están siendo salvados, extra ecclesiam nulla salus podría venir a significar algo tan banal como"solo los salvados son salvados". Por otro lado, mucho más seriamente, se podría caer en el error apuntado por la Mystici Corporis, o sea, una separación entre una Iglesia visible y otra invisible.

Por ello, este cambio de perspectiva no se dio sin conflictos. En 1962, se entregó a los padres conciliares un primer esquema De Ecclesia, elaborado por la comisión teológica, proponiendo una identificación entre Iglesia Católica Romana e Iglesia de Cristo y unos criterios meramente externos para delimitar quien era miembro de la Iglesia. ${ }^{60}$ Tal redacción suscitó un vivo debate en el aula conciliar, con severas críticas de los cardenales Bea y Liénart. ${ }^{61}$ Por otro lado, el cardenal Ottaviani defendía una adherencia estricta a la teología de san Roberto Belarmino, refiriéndose a Suprema haec sacra para explicar el sentido del adagio extra ecclesiam nulla salus y temiendo que su alcance fuera reducido para tranquilizar a aquellos que se encuentran fuera de la Iglesia. ${ }^{62} \mathrm{Al}$ final del debate, quedó claro que la mayoría de los padres conciliares se oponían a una eclesiología jurídica, a la identificación estricta entre Cuerpo Místico e Iglesia Romana y a una soteriología que se centraba solamente en la Iglesia como medio de salvación para el individuo. ${ }^{63}$

Como resultado, se formó en el Concilio una subcomisión De Ecclesia, encargada de trabajar sobre el esquema. Esta añadió algunos cambios considerables al documento, presentando a los padres conciliares un nuevo texto en 1963. Sobre la relación Iglesia de Cristo e Iglesia católica, este leía:

presente donc un aspect communautaire : elle est de nature sociétaire et se réfère toujours à l’Église. Voilà précisément pourquoi l'adage « Hors de l’Église pas de salut » garde sa signification pour tous les hommes, bien que non de façon identique pour tous". (PHILIPS, L'Église et son mystère, 208; traducción mía).

60 Cf. Acta Synodalis sacrossanti concilii Vaticani II, 1/4, en Sesboué, Fuera de la Iglesia no hay salvación, 232-234.

61 Cf. Sesboú, Fuera de la Iglesia no hay salvación, 235-239.

62 Cf. ZuidDwegt, "Salvation and the Church", 174.

63 Cf. Noceti - Repole, Comentario ai documenti del Vaticano II. Lumen Gentium (2), 31. 
Esta Iglesia, verdadera Madre y Maestra de todas las Iglesias, constituida y ordenada en este mundo como una sociedad, es la Iglesia católica, dirigida por el Pontífice Romano y los obispos en comunión directa con él, aunque fuera de su edificio total es posible encontrar numerosos elementos de santificación, que en cuanto realidades propias de la Iglesia de Cristo impulsan a la unidad católica. ${ }^{64}$

Subsistía, por lo tanto, la identificación, aunque reconociendo la presencia de elementos de la Iglesia de Cristo fuera de la institución visible de la Iglesia católica. En relación a la segunda cuestión, se evita cuidadosamente hablar de miembros, utilizando en su lugar la imagen de la incorporación, cualificada por adjetivos:

No se incorporan real, pura y simplemente a la sociedad de la Iglesia más que los que reconocen la totalidad de su estructura y todos los medios de salvación instituidos en ella, y en su edificio visible están unidos a Cristo, que la gobierna por el soberano Pontífice y los obispos, es decir, por los vínculos de la profesión de fe, del sacramento, del gobierno y de la comunión eclesiástica. ${ }^{65}$

Este esquema, acogido más favorablemente en el aula capitular, se acerca a lo que dirá el documento final. De hecho, el párrafo 8 de la Lumen gentium retoma prácticamente el texto del esquema de 1963, cambiando, sin embargo, la formula est ecclesia catholica por la formula subsistit in ecclesia catholica, que sería objeto de largos debates en el post Concilio. ${ }^{66}$

En cuanto a los miembros de la Iglesia, la operación es análoga. El documento final retoma y profundiza el texto de 1963.

A esta sociedad de la Iglesia están incorporados plenamente (plene ecclesiae societati incorporantur) quienes, poseyendo el Espíritu de Cristo, aceptan la totalidad de su organización y todos los medios de salvación establecidos en ella, y en su cuerpo visible (in eiusdem compage visibili) están unidos con Cristo, el cual la rige mediante el

64 Acta Synodalis sacrossanti concilii Vaticani II, II/1, pp. 219-220, en SESBouÉ, Fuera de la Iglesia no hay salvación, 240.

65 Acta Synodalis sacrossanti concilii Vaticani II, II/1, p. 220, in SesbouÉ, Fuera de la Iglesia no hay salvación, 241.

66 Para una interpretación de la fórmula, cf. CONGREGACión PARA LA DOCTRINA DE LA $\mathrm{FE}$, Respuesta a algunas preguntas acerca de ciertos aspectos de la doctrina sobre la Iglesia, 29 de junio de 2007. 
Sumo Pontífice y los Obispos, por los vínculos de la profesión de fe, de los sacramentos, del gobierno y comunión eclesiástica. ${ }^{67}$

El comentario de Gérard Philips sobre este párrafo presenta varios puntos de interés. Él remarca que los elementos externos de pertenencia a la Iglesia son enumerados exactamente como lo hace san Roberto Belarmino, ${ }^{68}$ pero a estos viene antepuesto el elemento espiritual: Spiritum Christi habentes.

Ahora bien, si el motivo principal de subrayar la vinculación espiritual a la Iglesia en primer lugar era hacer ver que una pertenencia meramente material a la Iglesia no es suficiente, ${ }^{69}$ esto abre también la posibilidad de considerar un cierto modo de incorporación a la Iglesia en aquellos que no comparten los elementos materiales. Tal idea es reforzada por el adjectivo plene, que acompaña al verbo incorporantur. Como hace ver Philips, este modo de hablar hace suponer que hay modos de unión incompleta. ${ }^{70}$

La disposición de las distintas categorías de personas en los números hace pensar que el Concilio presenta una gradación. En primer lugar, se dirige a los que se incorporan plenamente a la Iglesia; luego a los que no están plenamente incorporados a ella, sea porque aún no recibieron el bautismo, en el caso de los catecúmenos, sea porque "no aceptan la totalidad de su organización y todos los medios de salvación instituidos en ella" (LG 14), en los casos de los bautizados no católicos. Por último, se dirige a aquellos que están "ordenados" a la Iglesia, pero no son parte de ella, es decir, los no-cristianos. De esta manera, toda la humanidad es considerada en relación con la Iglesía y, por lo tanto, en relación con la salvación, sea ya como plenamente incorporada a ella, sea imperfectamente asociada o al menos ordenada a la Iglesia. ${ }^{71}$ Así el documento intenta resolver la cuestión eclesiológica sin apelar a una Iglesia invisible, sino

\footnotetext{
Lumen gentium, 14.

Cf. PHILIPS, L'Église et son mystère, 196.

Cf. PHILIPS, L'Église et son mystère, 194.

Cf. PHILIPs, L'Église et son mystère, 194.

1 El comentario español a la Lumen Gentium dirigido por Morcillo González prefiere dividir a los hombres en dos categorías: aquellos que pertenecen a la Iglesia, sea perfectamente sea imperfectamente, y aquellos solamente ordenados a ella, incluyendo los cristianos no-católicos en la categoría de los que pertenecen a la Iglesia, cf. Casimiro Morcillo GonzÁlez (dir.), Comentarios a la Constitución Lumen Gentium Sobre la Iglesia, Madrid, BAC, 1966, 324-327. Sin embargo, la distinción entre los párrafos 14, sobre los católicos y catécumenos, y 15, sobre los demás
} 
afirmando la existencia de una única Iglesia, a la que, sin embargo, se dan grados diversos de incorporación, más o menos perfectos.

En resumen, ¿qué propone la Lumen gentium acerca del adagio extra ecclesiam nulla salus y de su sentido? En primer lugar, la necesidad de la Iglesia para la salvación es expresamente reafirmada (n. 14), pero esta necesidad se realiza en modos diversos para distintos grupos de personas, dado que hay múltiples elementos de la verdadera Iglesia fuera de la estructura visible de la Iglesia católica (n. 8). Así, los católicos se incorporan plenamente en la Iglesia de Cristo, y deben perseverar en ella para alcanzar la salvación. Esta necesidad de incorporarse visiblemente a la Iglesia alcanza a todos los que reconocen en ella la Iglesia instituida por Cristo como necesaria a la salvación.

En relación a los cristianos no católicos, se reconoce que están de algún modo unidos a la Iglesia (n. 15) gracias a los elementos de la verdadera Iglesia presente entre ellos. De tal modo el Concilio ya no menciona el votum Ecclesiae como necesario para su salvación, pues esta se haría por medio de tales elementos de verdad y gracia. ${ }^{72}$ Tal desarrollo confirma el influjo del movimiento ecuménico en el cambio de perspectiva eclesiológica y en la elaboración misma de la Lumen Gentium. De hecho, parte considerable de los elementos más novedosos del documento se encontraban en el esquema preparatorio del documento elaborado por el Secretariado para la Unidad de los Cristianos, escrito paralelamente al de la Comisión Teológica que fue presentado a los padres conciliares. ${ }^{73}$

Finalmente, se reconoce la actuación de la gracia divina y la posibilidad de la salvación para los no cristianos, aún en aquellos que no reconocen explícitamente a Dios, a Cristo y a la Iglesia sin culpa de su parte, si buscan a Dios según el juicio de la conciencia o por lo menos se esfuerzan por llevar una vida recta (n. 16). Esta gracia ordena sus esfuerzos en algún modo a la Iglesia de Cristo. Aquí tampoco se menciona un votum Ecclesiae o la necesidad de la fe sobrenatural

cristianos, y el uso de un lenguaje distinto ("incorporantur" en el núm. 14 y"coniuncti" en el núm. 15) hace pensar que es mejor mantener tres categorías distintas.

72 De hecho, Francis Sullivan llega a afirmar que la teoría del votum ha sido completamente abandonada en lo que se refiere a los demás cristianos, y mantenida, implícitamente con relación a los no cristianos. Cf. Sullivan, Salvation Outside the Church?, 152.

73 Cf. NocetI - Repole, Comentario ai documenti del Vaticano II. Lumen Gentium (2), 21-22. 
como causa de salvación, sino más bien una voluntad y conciencia rectas bajo el influjo misterioso de la gracia.

\section{4. ¿CONTINUIDAD O RUPTURA EN LA LUMEN GENTIUM?}

Cabe ahora la pregunta sobre la continuidad o la ruptura entre la doctrina católica anterior y posterior a la Lumen gentium. Debemos aclarar cuál fue la actitud del Concilio con relación al Magisterio y a la teología anterior, y, por lo tanto, cómo se deben leer sus declaraciones. Entre los teólogos que han llevado a cabo estudios sobre el tema, las posiciones son diversas respecto a lo que realmente ha significado la aportación de la Lumen gentium. Mientras algunos enfatizan el aspecto de ruptura, otros prefieren subrayar la continuidad. Así encontramos en el estudio de Bernard Sesboué la afirmación de que, aunque el adagio clásico extra ecclesiam nulla salus no fue contradicho por el Concilio, sí había sido abandonado, de manera que se podría pensar que "ha acabado su carrera". ${ }^{74}$ Es más, él se interroga si no sería oportuno una declaración oficial del Magisterio que se distanciara explícitamente de tal formulación. ${ }^{75}$ Encontramos una posición semejante en el comentario de Dario Vitali al capítulo II de la Lumen Gentium, que considera que el número 16 de la Constituición supera los límites estrechos de la afirmación. ${ }^{76}$

Por otro lado, Gérard Philips declaró en su comentario que la opinión de los que pensaban que la Iglesia romana había abandonado su pretensión de monopolio en la tarea de conducir los hombres a la salvación no era exacta ni del punto de vista histórico ni del punto de vista teológico. ${ }^{77}$ Debemos, por lo tanto, evaluar las dos opiniones en su argumentación interna y confrontarlas con el Magisterio de la Iglesia al respecto.

En cuanto a la posición de Sesboué, el presupuesto necesario (aunque no claramente formulado) para proponer una ruptura doctrinal, es reconocer en el uso dogmático de la fórmula un error; error justificado por las circunstancias históricas, pero aun así, error.

\footnotetext{
SESBOUÉ, Fuera de la Iglesia no hay salvación, 338.

Cf. Sesboué, Fuera de la Iglesia no hay salvación, 404.

En Noceti - Repole, Comentario ai documenti del Vaticano II. Lumen Gentium (2), 201.

77 Cf. PHILIPS, L'Église et son mystère, 186.
} 
De hecho, el teólogo afirma que sería la capacidad de corregirse en tal caso que expresaría un aspecto esencial de la verdad conservada en la Iglesia y su Magisterio. ${ }^{78}$

Ahora bien, ¿tal concepción es compatible con el modo en que la Iglesia entiende la infalibilidad de su Magisterio? Sesboué sabe que esta cuestión es delicada, y por lo tanto confronta su tesis con lo que afirma la declaración Mysterium ecclesiae, de la Congregación para la Doctrina de la Fe, del $1973 .^{79} \mathrm{Tal}$ documento afirma en modo equilibrado la verdad fundamental y limitación histórica de las formas con las cuales el Magisterio enseña. La posición de Sesboué subraya la contingencia histórica de las fórmulas, pero no suficientemente su valor de verdad. Es difícil conciliar su posición en relación al adagio extra ecclesiam nulla Salus, afirmado en varias ocasiones y en modo solemne por el Magisterio ${ }^{80}$ al punto de ser referido como dogma, con tales afirmaciones como las que encontramos en la declaración:

De lo dicho anteriormente sobre la extensión y las condiciones de la infalibilidad del Pueblo de Dios y del Magisterio eclesiástico, se sigue que de ningún modo está permitido a los fieles admitir en la Iglesia solo una "fundamental" permanencia en la verdad, que, como algunos sostienen, se puede conciliar con errores diseminados por todas partes en las sentencias que enseña como definitivas el Magisterio de la Iglesia, o en lo que profesa sin duda de ningún género el Pueblo de Dios en materia de fe y costumbres. ${ }^{81}$

Es difícil negar que un axioma declarado tan frecuentemente sea expresión legítima, si no de un dogma en sentido propio, al menos de una verdad de fe católica. Además, el uso de la expresión por el Catecismo de la Iglesia Católica, ${ }^{82}$ y la reafirmación del contenido

78 Cf. Sesboué, Fuera de la Iglesia no hay salvación, 354.

79 Cf. Sesboué, Fuera de la Iglesia no hay salvación, 387-393.

80 Para declaraciones del Magisterio al respecto: Pelagio II (DH 469); Fórmula de Fe a los Albigenses de Inocencio III (DH 792); Iv Concilio de Letrán (DH 802); Bonifacio vIII (DH 870); Clemente vi (DH 1051); Decreto Pro Iacobitis del Concilio de Florencia (DH 1351); Gregorio XVI (DH 2730); y Pío IX, calificando el principio de Catholicum dogma (DH 2867), cualificación que es repetida por el decreto Suprema haec sacra (DH 3866).

81 Congregación para la Doctrina de la Fe, Mysterium Ecclesiae, 05 de julio de 1973, 4.

82 Cf. Catechismus Catholicae Ecclesiae, Ciudad del Vaticano, Libreria Editrice Vaticana, 1997, n. 846. 
por parte del Magisterio reciente ${ }^{83}$, remitiendo a la autoridad de los Padres, ${ }^{84}$ contradicen la idea de que la Iglesia tenga la intención de abandonar la fórmula.

La posición de Gérard Philips, por lo tanto, parece más coherente con la interpretación que el Magisterio ha dado del Vaticano in y que el mismo papa Juan XXIII propuso en su discurso de apertura del Concilio, al afirmar que este debería estudiar y exponer en conformidad con las exigencias del tiempo la doctrina "cierta e inmutable". ${ }^{85}$ Tal posición, sin embargo, no carece de dificultades en la interpretación de la formula clásica extra ecclesiam nulla salus.

No es difícil encontrar teólogos que, adhiriendo formalmente al adagio, lo interpretan en modo genérico, sin considerar la necesidad de la Iglesia para la salvación de cada individuo. Así, por ejemplo, Francis Sullivan reduce la substancia de la doctrina a la afirmación de que Dios ha asignado a la Iglesia un papel necesario en la economía divina de la salvación, ${ }^{86}$ y Giacomo Canobbio, aun divergiendo de la interpretación puramente parenética, no dogmática, que Sesboué atribuye al adagio, ${ }^{87}$ afirma la "posibilidad" de la salvación del individuo fuera de la Iglesia pero también el "deber" de referirse a ella, ya que la Iglesia es manifestación definitiva de lo que Dios piensa para la humanidad. ${ }^{88}$

La misma tendencia se encuentra en el documento de la Comisión Teológica Internacional El Cristianismo y las religiones. ${ }^{89}$ Aunque el documento afirma la única mediación de Cristo para la

83 Cf. Juan Pablo II, Redemptoris missio, 07 de diciembre de 1990, 9; y Congregación para la Doctrina de la Fe, Dominus Iesus, 06 de agosto de 2000, 20.

84 Congregación para la Doctrina de la Fe, Dominus Iesus, nota 80, con referencia a san Ireneo de Lyon y san Cipriano de Cartago.

85 JuAN XXIII, “Discurso en la inauguración del Concilio Vaticano II", AAS 54 (1962) 792.

86 Cf. Sullivan, Salvation Outside the Church?, 151.

87 Cf. CAnobbio, "Necessità (della Chiesa)", in Gianfranco Calabrese - Philip Goyret - Orazio Piazza (eds.), Dizionario di Eclesiologia, Roma, Città Nuova, 2010, 948.

88 Cf. CAnobbio, "Necessità (della Chiesa)", 962.

89 COMisión TeOlógica Internacional, El Cristianismo y las religiones, texto oficial latino publicado en Christianismus et religiones, Gregorianum 79 (1998) 427-472. Texto original español en <https://www.vatican.va/roman_curia/congregations/ cfaith/cti_documents/rc_cti_1997_cristianesimo-religioni_sp.html\#Conclusi $\%$ C3\%B3n> [consulta: 03-09-2021]. 
salvación ${ }^{90}$ y subraya el rol soteriológico indispensable de la Iglesia, ${ }^{91}$ las expresiones utilizadas denotan una cierta incomodidad frente a la formulación tradicional de extra ecclesiam nulla salus. Tal actitud parece nacer de la intención de la Comisión de alejarse de lo que denomina "eclesiocentrismo exclusivista", la posición asociada a Leonard Feeney ${ }^{92}$ que niega la posibilidad de salvación de aquellos que no pertenecen visiblemente a la Iglesia..$^{93}$

El documento, entre los números 66-70, propone un comentario de Suprema Haec Sacra y los números de Lumen Gentium tratados en este artículo para aclarar la posición católica sobre el tema. Sin embargo, la exposición del decreto del Santo Oficio comete una imprecisión terminológica que disminuye considerablemente el énfasis de este documento en la necesidad de la Iglesia para la salvación. Mientras el decreto afirmaba que la Iglesia es el medio general para la salvación, ${ }^{94}$ la Comisión Teológica utiliza el término ayuda, ${ }^{95}$ reduciendo el peso que el Santo Oficio quiso dar no solamente a la necesidad de precepto, sino también de medio, de la Iglesia para la salvación. A continuación, al comentar la Lumen Gentium, el documento interpreta el hecho de que la afirmación de la necesidad de la Iglesia para la salvación sea dirigida explícitamente a los católicos como una limitación del principio a aquellos que conocen esta necesidad. ${ }^{96}$ Más bien sería correcto decir que el principio es siempre válido, aunque solo genere una obligación de adherirse visiblemente a la Iglesia en la medida en que el principio es conocido.

El documento concluye esta sección aseverando que el sentido original de la frase sería parenético, y que solamente al integrarla en la afirmación de que extra Christum nulla salus es posible armonizarla con la llamada universal a la salvación. ${ }^{97}$ Esta conclusión resulta particularmente frágil en vista del objetivo global del documento de presentar una visión soteriológica cristocéntrica. De hecho, un teólogo

\footnotetext{
COMisión TeOlógica Internacional, El Cristianismo y las religiones, n. 49.

Comisión TeOlÓgica InTERnacional, El Cristianismo y las religiones, n. 49c. También 56 y 81.

Comisión Teológica Internacional, El Cristianismo y las religiones, n. 66.

Comisión Teológica InTernacional, El Cristianismo y las religiones, n. 10.

94 Congregación del SAnto Oficio, decreto Suprema haec sacra, 08 de agosto de 1949, in DH 3870.

95 Comisión Teológica Internacional, El Cristianismo y las religiones, n. 66.

96 Comisión TeOlógica InTERnacional, El Cristianismo y las religiones, n. 67.

97 Cf. COMisión Teológica Internacional, El Cristianismo y las religiones, n. 70.
} 
del pluralismo religioso como John Hick defiende que el exclusivismo cristiano es un óbice a una visión soteriológica universalista y aplica a las afirmaciones dogmáticas tradicionales un proceso exegético que busca subrayar su significado original mitológico o poético. ${ }^{98}$ ¿Si tal operación es posible para alargar el sentido de la necesidad de la Iglesia para la salvación, porque sería ilícito para extenderla más allá de la única mediación de Cristo?

Una interpretación teológica en pleno acuerdo con la hermenéutica del Concilio propuesta por Benedicto XVI necesita no solamente reconocer el valor de la afirmación tradicional, sino también evitar reducirla a una "fórmula vana", como advertía Pío XII en la Humani Generis. ${ }^{99}$ ¿Qué ha significado, entonces, el Concilio para la doctrina en cuestión?

Según Gérard Philips, el trabajo de los teólogos conciliares, ha permitido "desplazar suficientemente los acentos para llegar a una exposición más equilibrada". ${ }^{100}$ Desplazar los acentos. Esta expresión sintetiza bien la obra conciliar en este aspecto, pero necesita una explicación. Mauro Gagliardi presenta la teología católica bajo un principio que llama principio sintético, o sea, un nexo entre aspectos aparentemente contradictorios, pero que, tomados juntos y jerárquicamente ordenandos, revelan la verdad de las cosas. ${ }^{101}$ Así, puede darse un error sea por la negación de uno de los dos aspectos, sea por un cambio de acento, fijándose en lo secundario en detrimento de lo esencial. ${ }^{102}$

Podemos así interpretar la afirmación de Philips en el sentido de que la teología anterior al Vaticano is presentaba un desequilibrio en la consideración de los dos principios que se debe tener en cuenta al considerar el tema de la salvación. ¿Cuáles son estos principios?

98 Por ejemplo, en John Hick, God and the Universe of Faiths, Oxford, Oneworld Publications, 1993, 123-132, donde el autor analiza el desarrollo doctrinal de la afirmación de que fuera de la Iglesia no hay salvación o en John Hick, God Has Many Names, London, McMillan Press LTD, 1980, 53-56, donde expresa su idea de que la divinidad de Cristo, base del exclusivismo soteriológico, corresponde a una idea mitológica.

99 Cf. Pío XII, Humani Generis, 12 de agosto de 1950, 21.

100 "Déplacer suffisamment les accents de façon à parvenir à une exposé plus équilibré" (PHILIPs, L'Église et son mystère, 201).

101 Cf. Mauro Gagliardi, La verità é sintetica. Teologia dogmatica cattolica, Siena, Edizioni Cantagalli, 2017, 33-35.

102 Cf. Gagliard, La verità é sintetica, 31-32. 
Dominus Iesus los enuncia: la necesidad de la Iglesia para la salvación y la voluntad salvífica universal de Dios. ${ }^{103}$ La doctrina católica, según el principio sintético debe armonizar ambos principios. Sin duda el Magisterio anterior al Vaticano II daba más énfasis a la necesidad de la Iglesia para la salvación, y el Concilio buscó enfatizar el aspecto de la voluntad salvífica universal de Dios.

¿Este énfasis justifica el optimismo soteriológico postconciliar? El teólogo americano Ralph Martin denunció tal optimismo, al menos en el caso de los no cristianos, como una interpretación parcial de la Lumen gentium, ${ }^{104}$ que no tiene en cuenta la advertencia del Concilio de que "con mucha frecuencia" los hombres se dejan engañar por el maligno y se exponen a la desesperación extrema. ${ }^{105}$ Según Martin, una cierta interpretación recibida de la Lumen gentium hace un salto lógico de la posibilidad de la salvación para los no cristianos a la probabilidad de la salvación. ${ }^{106}$

La doctrina del Vaticano II sin duda considera con mayor amplitud la existencia de la ignorancia no culpable entre los no-católicos y la acción de la gracia fuera de los límites visibles de la Iglesia. Sin embargo, el texto de la Lumen gentium no implica una soteriología universalista. Tampoco parece justificar la afirmación de que las religiones no-cristianas serían medios de salvación, como defiende Gerard O'Collins. ${ }^{107}$ Cabe más bien hablar, con Echeverría, de un accesibilismo, lo que significa la posibilidad y no la certeza de la salvación para los no cristianos. ${ }^{108} \mathrm{Tal}$ posición no niega la verdad del principio de que fuera de la Iglesia no hay salvación.

103 Cf. Congregación para la Doctrina de la Fe, Dominus Iesus, n. 20.

104 Cf. Ralph Martin, Will Many Be Saved?: What Vatican II Actually Teaches and its Implications for the New Evangelization, Grand Rapids, MI, William B. Eerdmans Publishing Company, 2012.

105 Cf. Lumen gentium 16. Esta advertencia es tenida en cuenta en el comentario de Morcillo González, que afirma que"Sin pertenecer, pues, a la Iglesia es posible, pero es muy difícil, salvarse", y hace derivar de tal hecho el llamado a la misión en el número 17: Morcillo GonzÁlez, Comentarios a la Constitución Lumen Gentium, 329.

106 Martin, Will Many Be Saved?, 55.

107 Cf. Gerard O'Coluins, The Second Vatican Council on Other Religions, Oxford, Oxford University Press, 2013, 73-79.

108 Cf. Eduardo ECHEVARRíA, "The Salvation of Non-Christians? Reflections on Vatican II's Gaudium et Spes 22, Lumen Gentium 16, Gerald O'Collins, S.J. and St. John Paul II («For by His Incarnation the Son of God has united himself in some 


\section{CONCLUSIÓN}

Para terminar este estudio, buscaremos presentar en modo ordenado una síntesis de lo que enseña el Magisterio sobre la necesidad de la Iglesia para la salvación, teniendo en cuenta los distintos pronunciamientos magisteriales, integrando la enseñanza del Vaticano in y la del Magisterio anterior. Para esta tarea buscaremos aplicar los distintos grados de autoridad de los pronunciamientos magisteriales como enunciados en la Nota doctrinal ilustrativa de la fórmula conclusiva de la Professio fidei, publicada por la Congregación para la Doctrina de la $\mathrm{Fe}^{109}$ a los puntos que constituyen la doctrina contenida en el adagio extra ecclesiam nulla salus.

1. La Iglesia es necesaria para la salvación: Esta verdad debe ser firmemente creída. ${ }^{110}$ La frecuencia y solemnidad de esta proclamación en el Magisterio y la Tradición de la Iglesia, y su vinculación con la Revelación hace pensar que se trate de una verdad de fe en sentido propio. ${ }^{111}$ De hecho, la Lumen gentium la afirma expresamente. ${ }^{112}$

2. La voluntad salvífica universal de Dios: El Vaticano II quiso remarcar especialmente este aspecto, con origen directo en la Revelación: «Dios quiere que todos los hombres se salven y lleguen al conocimiento de la verdad» (1 Timoteo 2,4). Aunque tal afirmación no se encuentre en una proclamación dogmática solemne, ha sido una constante en la enseñanza de la Iglesia ${ }^{113}$ y las distintas condenaciones a proposiciones contrarias ${ }^{114}$ permiten afirmar que se trata por lo menos de una doctrina que se debe considerar como definitiva. ${ }^{115}$

fashion with every man»: Gaudium et Spes §22.8)", Angelicum 94/1 (2017) 120 (93-142).

109 Cf. Congregación Para la Doctrina de la Fe, Nota doctrinal ilustrativa de la fórmula conclusiva de la Professio fidei, 29 de junio de 1998, 5-10.

110 Cf. Congregación para la Doctrina de la Fe, Dominus Iesus, n. 20.

111 Cf. Congregación para la Doctrina de la Fe, Nota Doctrinal Ilustrativa de la fórmula conclusiva de la Professio fidei, 5.

112 Cf. Lumen gentium, 14.

113 Por ejemplo, en el Sínodo de Quiercy (h. 853 d.C.): "Deus omnipotens omnes homines sine exceptione vult salvos fieri" (DH 623).

114 Cf. Ludwig Oтт, Manual de teología dogmática, Barcelona, Herder, 1969, 367-371, traducción española de IDEM, Grundriss der katholischen Dogmatik, Freiburg in Br., Herder, ${ }^{7} 1965$.

115 Cf. Congregación Para la Doctrina de la Fe, Nota doctrinal ilustrativa de la fórmula conclusiva de la Professio fidei, nn. 7-9. 
3. En el período patrístico y medieval no se veía cómo estos dos principios pudieran ser contradictorios. El evangelio se consideraba suficientemente difundido para que todos los hombres tuvieran la oportunidad de creer y que, por lo tanto, los no cristianos, salvo raras excepciones, deberían ser culpables de incredulidad. A partir de los descubrimientos geográficos de la Edad Moderna, los cristianos se dieron cuenta de que apenas una mínima porción de la humanidad había tenido contacto con el evangelio y, en consecuencia, la teología y el Magisterio buscaron medios de conciliar los dos principios. ${ }^{116}$ Desde Pío Ix hasta el decreto Suprema haec sacra, se afirmó la posibilidad de esta conciliación por medio de las doctrinas de la ignorancia no culpable y del votum Ecclesiae.

4. La no culpabilidad de aquellos que sin falta propia son ignorantes acerca de la Iglesia siempre ha sido reconocida como un elemento necesario para que puedan alcanzar la salvación. La Lumen gentium acoge esta doctrina, ${ }_{117}^{117}$ mientras añade una precisión importante: no se requiere para caracterizar la ignorancia un total desconocimiento de la existencia de la Iglesia, sino que basta ignorarla ut necessariam. $\mathrm{O}$ sea, el Concilio admite que existen limitaciones no solamente históricas o geográficas para la adhesión a la Iglesia, sino también psicológicas, de modo que alguien que conociera la Iglesia, pero que, sin culpa de su parte, no la reconociera como necesaria para la salvación, se incluiría también en el número de los ignorantes.

5. Finalmente no basta un elemento negativo (ausencia de culpabilidad) para alcanzar la salvación sin pertenecer visiblemente a la Iglesia. Es necesario un elemento positivo, de vinculación a la Iglesia. En el Magisterio preconciliar gradualmente se estableció la doctrina del votum Ecclesiae para responder a tal necesidad. Tal doctrina no ha sido propuesta con carácter definitivo como verdad revelada, sino más bien como una explicación de la armonía entre los dos principios necesarios. Tal doctrina era, por lo tanto, objeto no de un acto de fe, sino del obsequio religioso. ${ }^{118}$

6. Dado que la doctrina del votum no es parte de la Revelación, puede dejar de ser propuesta por el Magisterio. De hecho, esto parece hacer la Lumen gentium, pues el concepto de participación en la

116 Cf. SesBoué, Fuera de la Iglesia no hay salvación, 127-168.

117 Cf. Lumen gentium, 14.

118 Cf. Congregación para la Doctrina DE la Fe, Nota doctrinal ilustrativa de la fórmula conclusiva de la Professio fidei, n. 10. 
Iglesia en modo analógico, los vestigia Ecclesiae entre los cristianos no-católicos, y la gracia concedida a los que se esfuerzan por conocer y seguir la voluntad de Dios en sus propias conciencias entre los no cristianos, constituyen el elemento positivo de unión a la Iglesia, dispensando así la necesidad de un votum Ecclesiae.

Así, podemos decir que la obra del Concilio no consistió en negar la necesidad de la Iglesia para la salvación en nombre de la voluntad salvífica universal de Dios. Y no podría hacerlo, dado que tal afirmación es parte integral de la fe católica. Lo que hizo fue proponer una nueva elaboración doctrinal para conciliar ambos aspectos, a la luz del desarrollo teológico del siglo xx. Esta elaboración se coloca en el nivel del Magisterio ordinario, y debe ser recibida por todos los católicos con el obsequio religioso de la inteligencia y la voluntad. Interpretado bajo esta perspectiva, el Concilio profundiza en la explicación de la verdad de fe extra ecclesiam nulla salus, y se pone, por lo tanto, en armonía con el Magisterio anterior y la Tradición de la Iglesia.

$\mathrm{Al}$ acoger y aplicar el Concilio Vaticano II, la Iglesia debe reconocer su sentido auténtico, también en el tema de la necesidad de la Iglesia para la salvación. El ecumenismo, el diálogo interreligioso, la misión ad gentes y la nueva evangelización deben ser expresiones concretas de estos dos principios que la Lumen gentium volvió a enfatizar, en continuidad dinámica con el magisterio anterior: Dios quiere que todos los hombres se salven y lleguen al conocimiento de la verdad, y esta Iglesia, peregrina en el mundo, es necesaria para la salvación. 
